\title{
Ethics and CSR Research in Top Ranked IS Journals, 1980-2013: A Developing Trend or Anomaly?
}

\author{
Joseph W. Weiss \\ Bentley University \\ Waltham, MA 02452 \\ jweiss@bentley.edu
}

\begin{abstract}
This study analyzes scholarly research on ethics and CSR (Corporate Social Responsibility) in selected top ranked journals in the Information Systems field from 1980-2013. The purpose is to identify and examine the salience of ethics and CSR concepts and approaches in IS journals. Eighty-six articles were analyzed using bibliometric methods. Results show an increase in the use of ethics and CSR concepts from 1.24 to 2.23 percent of articles published during this period; the topics of privacy and principles were used in the sample of most cited articles; quantitative methods were more prevalent than qualitative methods; and non-normative (descriptive) ethical and CSR approaches slightly exceeded the use normative ('ought'/'should') orientations, which may indicate an integrative or fragmented state of development of IS as a developing field. We discuss whether or not these results signal a developing trend or an anomaly regarding the inclusion of ethics and CSR in the evolving field of IS research.
\end{abstract}

\section{Introduction}

The field of Information systems (IS) has evolved over three decades, during which time scholars have argued over the role IS research should play. Some scholars argue that IS members should pursue a focused, disciplined definition of IS with regard to its central "boundary knowledge elements" [3; 18; 19]. A contrasting view $[7 ; 24]$ envisions the field as more porous, interactive, and open to influences from other disciplines.

Scholars who have analyzed the evolution of IS research paradigms and methodologies [10] have challenged the direction of IS. Chen and Hirschheim [ 10,197 ] in particular asked: "What changes are manifested in journal publications? Is the field making progress regarding pluralism in IS research? How will the field's publications practices change in the future?"
Their study of 1893 articles published in "eight major IS publication outlets between 1991 and 2001" found that that a positivist paradigm dominated research publications. A preponderance of survey research using quantitative methods led these scholars to conclude that if the IS field was to include pluralism in scholarly publications, "it would have to find ways to fundamentally change the publication practices of the journal system, including the current tenure and promotion system, which pose considerable obstacles for the acceptance of alternative paradigms"[Ibid].

Bernroider, E, A. Pilkington, J. Córdoba, (2013)[ 6] recently argued that IS as a field is in flux, continually changing, interacting, and competing with other disciplines such as General Management, Business Strategy, Marketing, and Ethics and Governance, among others. As a dyanmic discipline, IS should, they argue, embrace a wide range of different disciplines and continue to interact with them. [Ibid.]

Related to this debate and the evolution of the IS field generally is the question posed in this study: To what extent are ethics and social responsibility concepts used in top ranked IS research journals?

\section{Ethics and CSR Matter}

What concepts, frameworks, and perspectives do ethics and CSR offer other fields? Ethics, as part of philosophy, is a mature discipline. It involves descriptive as well as normative ('ought'/ 'should') dimensions of behaviours, beliefs, values, and conduct. Ethics also combines legal theory and politics as well as philosophical and historical domains as subjects of inquiry [26].

"Business ethics" is part of applied ethics [26] that "examines ethical principles and moral or ethical problems that arise in a business environment" [23] and is relevant to aspects of business conduct-individual, 
groups, teams, organizations, and societies [4; 15;13]. Ethics has extended to other fields as sub-speciality areas such as marketing ethics, finance ethics, law and ethics, ethics and technology, medical ethics, and accounting ethics. Recent and ongoing national and global crises (such as Enron, the subprime lending crisis, the British Petroleum oil rig explosion and leak, and Flint Michigan's water disaster) have heightened the need for enforceable ethical and legal conduct codes in different industries.

CSR, corporate social responsibility, is a relatively young and evolving field. Howard Bowen's 1953 book, Social Responsibility of the Businessman, was the first noted use of this term, however CSR's mandate: an organization's primary obligation is to operate in a socially responsible manner to both stakeholders and stockholders [9]. Popular among corporations globally and locally, CSR is an influential movement that has influenced corporate codes of ethics and conduct, professional training, and university and practitioner research.

However, CSR along with business ethics, continues to be studied and debated with regard to its continued effectiveness as a field and discipline with identifiable and coherent research traditions. Lockett et al, 2006 [ , 20] concluded that regardless of it's important influences, CSR is "a field without a dominant paradigm." Dahlsrud (2006)[11] offered 37 definitions of CSR, some of the main dimensions that incorporate those definitions include stakeholders, social, economic, voluntariness, and environmental. Schwartz and Carroll (2008) [ 9 ] proposed five frameworks in the Business and Society field that can be used for research purposes: CSR, Business Ethics, Stakeholder Management, Sustainable Development, and Corporate Citizenship. Aguinis (2012) [1] presented a multidimensional research framework to help organize the field of future CSR research.

The fields of CSR and business ethics, are dynamic and interactive with other disciplines. The concepts, frameworks, and paradigms that have and continue to be adopted and incorporated may also indicate relevance and growth as well as fragmentation in the CSR and business ethics fields, as some critics assert. The question of interest here is, To what extent have major top ranked IS journals included ethics and CSR in their publications over the decades from the 1980's through 2013 ?

\section{Research Agenda and Methods}

While many bibliometric studies on CSR have focused on investigating CSR topics published in ethics and CSR related journals such as the Journal of Business
Ethics, Ethics Quarterly, and the like [14;20; 2], there is a trend of authors publishing ethics and CSR concepts in journals from different fields-see Figure 2 below. This study contributes to that trend.

Bibliometric methods $[16 ; 17]$

were used in this study to analyze citations from research published in eight selected top ranked IS journals. Bibliometrics is an empirical method of using data and information to generate "citation frequencies and general overview of publications within a certain field." [21].

A research of Web of Knowledge was performed using the key words "ethic*," "social responsibility", and "corporate social responsibility" in these IS publications: European Journal of Information Systems, Information Systems Journal, Information Systems Research, Journal of AIS, Journal of Information Technology, Journal of MIS, Journal of Strategic Information Systems, and MIS Quarterly. The selection of these journals was based on the following sources, The Association for Information Systems, "Senior Scholars' Basket of Journals," and the ACPHIS Information, Australian Council of Professors and Heads of Information Systems ranking.

IBM SPSS Text Analytics for Surveys was also used for this analysis. The abstracts of the articles were the open-ended text parameter used to determine the occurrences of words. Two categories were built from these results - 'ethics' and 'corporate social responsibility'. Each of these categories included variations of tense and forms of the word and also phrases that contained the word. The results of this analysis returned a true/false value for each category, which served as a guideline going forward. Three teams of graduate researchers worked independently and on overlapping assignments to check for accuracy, duplication of information, and omissions. Senior researchers were used to also check for accuracy. Several articles were discarded due to duplications, book reviews, or opinion pieces.

Eighty-six IS articles were then selected that met the criteria of representing a research article that used an approach and methodology that could be classified as empirical or theoretical, quantitative or qualitative, and normative or non-normative in orientation [20], as we explain below.

Limitations of the bibliometric methodology as used here are also found in Bakker et al (2006) [ 2 ] and include the following: incomplete coverage of journals, issues, page numbers; unsystematic patterns and incorrect information. To correct for such commonplace errors, four teams of graduate and undergraduate students were used along with senior researchers to cross-check and duplicate some analyses. 


\section{Data analysis and findings}

Figure 1 shows the increase of occurrences of ethics and CSR concepts and perspectives used as a percentage of total articles published from the 1980's through 2013. There is an increase by decade of $1.24 \%$ from the 1980's and 1990's to $1.8 \%$ through during 2000-2010, a slow and uneventful period with regard to ethics and CSR related articles appearing in these journals. From 2010-2013, there was a noticeable increase of $2.23 \%$ increase, although in absolute terms this would not be considered a strong percentage. There are several speculative reasons for this increase: during the 1997 to early 2000's the Dot.com collapse along Enron and other notable corporate scandals occurred impacting the national economy and drawing media attention.

The subprime lending crisis, then, coincided with a national recession, both jarring the global and national economies between 2007-2010. During this period, ethics and CSR, in particular, became more visible in business communities, the media, and in some scholarly publications [23].

\section{Figure 1. Ethics/CSR as a percentage of total IS} articles published 1980-2013

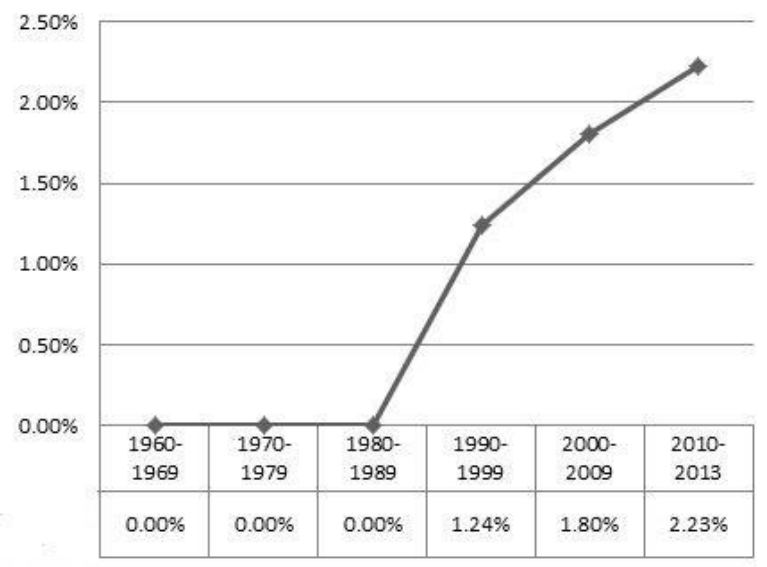

There are other possibilities for the increase in ethics and CSR related publications as shown in Figure 1 that would require additional research.

Relevant to this inquiry is a larger unpublished study that in Figure 2 extends the findings from the first figure to include the fields of marketing, accounting, management/project management, and knowledge management.

Figure 2. Ethics/CSR as a percentage of total articles in 5 fields Published 1980-2013

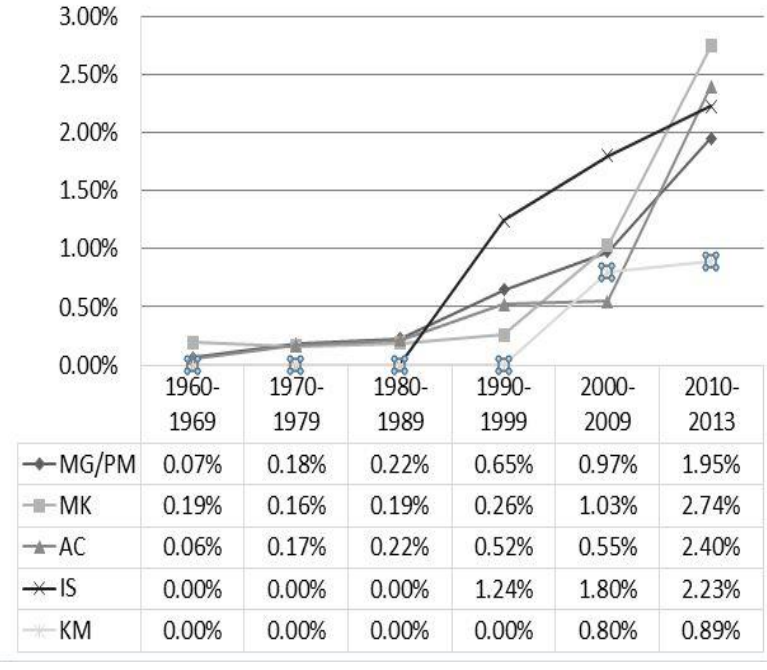

Figure 2 shows the field of IS is third with the percentage of ethics/CSR publications from 1980 through 2013. Marketing and accounting top ranked publications show greater increases in percentages of top ranked publications that include ethics and CSR, and greater increases from the 1990's through 2013. Generally, management journals (related to organizational behavior, leadership, strategy, and other general topics) have showed a tendency to publish more articles on CSR and ethics than journals in other fields. This is one of the first bibliometric studies, to our knowledge, to show results of ethics/CSR related publications in a number of different management related fields. The trend of such publications is increasing.

Also of interest is what we have termed the Ethics/CSR epistemological orientation of IS articles published in Table 1. Lockett et al [20] used this framework which indicates the type of methodology an author employed in an article as being either theoretical or empirical. Articles that used a theoretical orientation would also be classified as using either non-normative or normative ethical approaches [25]; whereas, articles that used empirical approaches would be characterized as having used either a qualitative or quantitative approach.

Lockett et al (2006) posited that the more a field, such as CSR in their case, matured, the more likely the nature of knowledge changes over time. So theoretical methods would give way to empirical studies that tested theories. Also, the more balance would be expected with a shift from qualitative to quantitative approaches. These authors noted that other external influences could also affected these approaches. 


\section{Table 1. Ethics/CSR Epistemological Orientation of IS Articles}

\begin{tabular}{|c|c|c|c|c|}
\hline \multicolumn{2}{|c|}{ Theoretical } & \multicolumn{2}{|c|}{ Empirical } & \\
\hline Non-Normative & Normative & Qualitative & Quantitative & Total \\
\hline 17 & 20 & 19 & 30 & 86 \\
\hline $19.77 \%$ & $23.6 \%$ & 22.09 & $34.88 \%$ & \\
\hline
\end{tabular}

The results from Table 1 indicate that there were more quantitative than qualitative articles published and there is not a significant difference between normative and non-normative theoretical articles. There are also more quantitative than and qualitative articles which, according to Lockett et al, could indicate a more maturing field that could also reflect a field that may be encouraging more positivist and lest interpretive research approaches with regard to Chen and Hirschheim's (2004)[ ] critique and findings. A more indepth analysis that examines particular journals would offer for insight on these observations.

\section{Observations and Conclusion}

The results of this focused, preliminary study suggest that the top ranked thought-leader journal editors, review boards, and submitting authors in the field of IS have been gradually and over decades accepting and producing more articles using ethics/CSR perspectives, concepts, and methodologies. While the amount of such articles in this genre has been somewhat sparse, the trend has been upward. The factors influencing these results is a project for further research. Whether or not and to what extent this trend continues to increase is yet to be seen.

Results also show that the top ranked journals in the IS field accept - and perhaps receive--fewer ethics/CSR related articles than do the top ranked journals in the marketing and accounting fields. This also is an invitation to future researchers.

With regard to the opening introductory statements about whether or not the IS field of research is and/or should be more focused on its own bounded knowledge and specializations, or be open and inviting to other disciplines, results here are mixed. The increasing yet small number of ethics/CSR articles in the top journals suggest the field may be more inviting to other research methods. This too is an observation in need of more investigation.

The emphasis of ethics/CSR research using more quantitative, empirical methods may suggest that a positivist approach is still prevalent [10]. However, qualitative empirical approaches and the percentages of theoretical orientations are also evident.

An obvious, important but intentional limitation of this study is the sample of top ranked IS journals used, which excludes books, practitioner journals, and other ranked publications in the IS field.

\section{Acknowledgements}

Two co-authors are recognized and thanked for the original in-depth study on which this paper is based: Tumennassan Bayar and Suzanne Zyngier. Several Bentley University MBA students also assisted with the research on this 2.5 year study.

\section{References}

[1] Aguinis, H. and Glavas, A. (2012). What We Know and Don't Know About Corporate Social Responsibility: A Review and Research Agenda. Journal of Management, 38(4), pp. 932-968.

[2] Bakker, F., Groenewegen, P. and Hond, F. (2006). A Research Note on the Use of Bibliometrics to Review the Corporate Social Responsibility and Corporate Social Performance Literature. Business \& Society, 45(1), pp.7-19.

[3] Baskerville, R., Lyytinen, K., Sambamurthy, V. and Straub, D. (2010). 'A Response to the Design-Oriented Information Systems Research Memorandum,' [Opinion Piece], European Journal of Information Systems , Advanced Online Publication (AOP) 20 (1): 11-15.

[4] Baumhart, R. (1968). An Honest Profit: What Businessmen Say About Ethics and Business, New York: Holt, Rinehart and Winston.

[5] Beets, S., Brower, H., and Lewis, B. (2013). 'The Quality of Business Ethics Journals: An Assessment Based on Application'. Business \& Society, 20(10), 1-26..

[6] Bernroider, E, A. Pilkington, J. Córdoba, (2013). 'Research in information systems: a study of diversity and inter-disciplinary discourse in the AIS basket journals between 1995 and 2011,' pp. 74-89.

[7] Bryant, A. (2008). 'The Future of Information Systems Thinking informatically,' European Journal of Information Systems 17 (6): 695-698.

[ 8 ] Carroll, Archie (1979). 'A Three Dimensional Conceptual Model of Corporate Performance', Academy Of Management Review, Vol. 4, No 4, 497-505.

[9] Carroll, A. and Schwartz, M. (2008). 'Integrating and Unifying Competing and Complementary Frameworks: The Search for a Common Core in the Business and Society Field'. Business \& Society, 47(2), 148-186. 
[10] Chen, W. and Hirschheim, R. (2004). 'A paradigmatic and methodological examination of information systems research from 1991 to 2001'. Information Systems Journal, 14, 197-235.

[11] Dahlsrud, A. (2008). 'How corporate social responsibility is defined: an analysis of 37 definitions,' Corporate Social Responsibility and Environmental Management, 15( 1), Pp. 1-62.

[12] de Bakker, F., P. Groenewegen, and F.den Hond, (2006). 'A Research Note on the Use of Bibliometrics to Review the Corporate Social Responsibility and Corporate Social Performance Literature,' Business \& Society, 45(1) March, pp. 7-19.

[13 ] Donaldson, T. (1982). Corporations and Morality, Englewood Cliffs, NJ: Prentice Hall.

[14] Ergi, C. and D. Ralston. (2008). 'Corporate responsibility: A Review of international management research from 1998 to 2007,'Journal of International Management, 14, pp. 319-339.

[15] Ferrell, O. , J. Fraedrich, J.. L. Ferrell. (2000). Business ethics: Ethical decision making and cases (4th ed.). Boston: Houghton Mifflin.

[ 16] Garfield E. (1996). 'A bibliometric analysis of science journals in the ISI database.' Science Citation Index. Journal Citation Reports. Printed guide to the microfiche edition of the SCI JCR.

[17 ] Glänzel W. (1996). 'A bibliometric approach to social sciences.' National research performance in 6 selected social science areas 1990-1992. Scientometrics. 35(3): 291-307.

[18] Hassan, N. and H. Will. (2006). 'Synthesizing Diversity and Pluralism in Information Systems: Forging a unique disciplinary subject matter for the information systems field,' Communications of the AIS 17 (7): 152-180.

[ 19] Hirschheim, R., Iivari, J. and Klein, H.K. (2004). 'Towards a Distinctive Body of Knowledge for Information Systems Experts: Coding ISD process knowledge in two IS journals,' Information Systems Journal 14 (4): 313-342. [20 ] Lockett, A., J. Moon, and W. Visser. (2006). 'Corporate Social Responsibility in Management Research: Focus, Nature, Salience and Sources of Influence,' Journal of Management Studies 43(1), pp. 115-136.

[21] Moed, H. (2002. 'The impact-factors debate: The ISI's uses and limits.' Nature , 415(6873), pp. 731-732.

[22] Schwartz, M. and A. Carroll. (2006). Integrating and Unifying Competing and Complementary Frameworks, The Search for a Common Core in the Business and Society Field, Business \& Society, 47(2), pp. 148-186.
[23] Solomon, R. (1991), Business Ethics, In: Peter Singer (Ed.), A Companion to Ethics, Malden, MA: Blackwell, 354 365.

[24]Somers, M. (2010). 'Using the Theory of the Professions to Understand the IS Identity Crisis,' European Journal of Information Systems 4 (19): 382-388.

[25] Swanson, D. (1999). 'Towards an integrative theory of business and society: a research strategy for corporate social performance,' Academy of Management Review, 24(3), pp. 506-521.

[26] Velentzas, J. and G. Broni. (2010). 'Ethical dimensions in the conduct of business: Business ethics, corporate social responsibility and the law.' International Conference on Applied Ethics, IOAC, pp. 795-819.

[27] Yelkikalan, N. and C. Köse. (2012). The' Effects of the Financial Crisis on Corporate Social Responsibility,' International Journal of Business and Social Science3.3 (Feb 2012): n/a. 